\title{
NEWS FROM THE SCHOOLS \\ THE APPLIED SOCIAL SCIENCE MODULAR SCHEME: BSc IN INFORMATION AND COMMUNICATION STUDIES: 1988
}

\author{
Kevin McGARRY \\ The Polytechnic of North London, London, United Kingdom
}

Received 20 July 1988

From September 1987 the BA in Librarianship and Information Studies has been phased out. In its stead is a pathway to this new degree entitled the Information and Communication Pathway. For the PNL it is the end of a 'stand alone degree' in librarianship. The pathway seeks to provide appropriate learning opportunities for students wishing to understand the world of information and to prepare themselves for the wide range of occupations in the storage, handling and communication of information.

The pathway takes a theoretical and analytical approach to three interrelated fields: information technology, librarianship and information science and mass communications. It also offers a wide range of practical skills for effective practice in the information professions.

One of the distinguishing features of the later years of this decade is the alignment of library schools with other subject departments. Strathclyde University, Glasgow is a notable example, and the innovative thrusts of this department in business information is indicative of a specialized focus. The Polytechnic of North London's School of Librarianship is integrated with a Faculty of Social Science and uses a social science scrutiny of the world as a basis for its specialized interests. Our course focuses on the information needs of urban communities and the context of social communication.

\section{Aims}

- To promote an appreciation of the contribution of the social sciences to an understanding of the role of communication and information systems in the contemporary world.

- To examine the technological, economic, political and social contexts of the production, distribution and consumption of information.

- To analyse the growth and development of the communications industry and related professions. 
- To equip students with the technical competencies and skills necessary for selecting, organizing and retrieving information.

- To impart to students the social and managerial skills necessary for the effective design and delivery of information services.

\section{Organization and structure}

The basic building block of the course is the unit of study. All units are of equal length -15 weeks, or one semester.

Full-time students normally take 24 units to complete the Honours degree programme. The units are designated by level - Preliminary, Intermediate and Final.

2.1. Preliminary Level. The Preliminary level is structurally distinct from the Intermediate and Final levels in that it operates 'horizontally' to provide all students whatever their pathway choice with an introduction to the conceptual framework, subject material, forms of analysis and methodology of the social sciences. The level is composed of four common foundation units:

The individual in society

Social history and social policy

Introduction to law

Information and society

These units represent the basic requirements for all five pathways: Health Studies; Policy Studies; Social Research; Social Work - and of course the one under discussion: Information and Communication.

On the successful completion of these core units the student then chooses four option units from the following eight offered at this level.

Economy and Society

Individual in Society

Information needs analysis

Political institutions and processes

Political philosophy and state intervention

Introduction to the administration of justice

Social structure and social processes

Social thought and social change.

The Intermediate and final levels operate 'vertically' to provide students with programmes of study facilitating progression to Honours standard through increasing specialization and competence.

Each of the five pathways has specified certain units as core, i.e. compulsory for students taking that pathway. The core units and designated options for the Information and Communication Pathway are: 
Semester $A$

Core

Computers and information access

Fundamentals of information retrieval

Designated options

Sources of information

Managing information services

Information systems analysis

Media and popular culture

Censorship, law and the regulation of culture

Local government and local politics *

Women in contemporary Britain *

Research methods *

Final Year

Semester $A$

Core

Principles and practice in information work. A

A placement-linked module.

Principles and practice in information work. B

Management-linked placement module.

Designated options

Information and communication in scientific communities

Documentation in a specified subject

Technology of data handling and transfer

Information software: data structures and techniques

Popular literature

Ethnic minorities and public policy

Data analysis
Semester $B$

Core

Cultures, information and communication

Economics and politics of information

Designated options

Organizing bibliographic information

Business information

Library and information work in a multi-cultural society

Information software: programming and design

Publishing and bookselling studies

The information professions

Computers in social research *

\author{
Semester B \\ Core \\ Information and communication \\ project.
}

New directions in information and communication technology.

\section{Designated options}

International communication systems

Automated indexing and retrieval systems

Intelligent information systems

Reading studies

Arts policy in Britain *

Immigrant communities: history and sources of information

Ethnic minorities and education. 
Those marked with an asterisk $\left({ }^{*}\right)$ are drawn from other pathways. In a radical departure from traditional practice, fieldwork or placement is now treated as a module and is assessed.

The following samples of student programmes illustrate possible routes through the information and Communication Pathway. Core modules are in italics. At the preliminary level the foundation core modules are the same for all students in the pathway. However, as the observant reader will have noticed, students will need firm and wise counselling in their choices. First year students who wish to choose the Information and Communication Pathway will be counselled to take the option: Information Needs Analysis.

Sample Student 1. Focus on traditional/orthodox librarianship

Intermediate level

Computers and information access

Fundamentals of information retrieval

Cultures information and communication

Politics of economics and information

Sources of information

Managing information services

Organizing bibliographic information

Organization of information services
Final level

Principles and practice in Information work (placement)

The information and communication project.

Documentation in a specified subject

Audio visual media: bibliographic retrieval systems.

Sample Student 2. Focus on information technology

Intermediate level

Computers and information access

Fundamentals of information retrieval

Cultures information and communication

Politics and economics of information systems

Sources of information
Final level

Principles and practice in information work

Information and communication project

New directions in communication and information

Technology of data handling 
Information systems analysis

Information software: programming and design

New technology and information services and transfer

Information software: data structures and techniques

Automated indexing and retrieval systems

Intelligent information systems.

Sample Student 3. Focus on the media and information work

Intermediate level

Computers and information access

Fundamentals of information retrieval

Cultures information and communication

Politics and economics of information

Media and popular culture

Press and broadcasting studies

Publishing and bookselling studies

Women in the media
Final level

Principles and practice in information and communication work placement modules

Information and communication project

New directions in communications and information

Audiovisual media: bibliographic and information retrieval systems

Popular literature

Reading studies

Arts policy in Britain.

Sample Student 4. Focus on inner city information work

Intermediate level

Computers and information access

Fundamentals of information retrieval

Cultures information and communication

Politics and economics of information

Managing information services

Local government and local politics

Library and information work in a multicultural society

Organization of information services for specific communities
Final level

Principles and practice in information work placement

Information and communication project

Popular literature

Ethnic minorities and public policy

Automated indexing and retrieval systems

Ethnic minorities and education * 


\section{Summary}

As with most degree courses the problem of integration is a major concern. The function of the Information and Communication Project is to enable the student to bring together the concepts and techniques learnt in the other modules. This bringing together must have a focus on a specific issue in librarianship, information work and communications. There is a secondary objective in that the student acquires the experience of researching and writing a lengthy report, and in the general presentation of information. We feel that the modular structure will give us sufficient flexibility to cope with the manifold and imminent unknowns of the nineteen nineties. 